\title{
Cognitive Trajectories after Postoperative Delirium
}

\section{Citation}

Saczynski, Jane S., Edward R. Marcantonio, Lien Quach, Tamara G. Fong, Alden Gross, Sharon K. Inouye, and Richard N. Jones. 2012. "Cognitive Trajectories after Postoperative Delirium." New England Journal of Medicine 367, no. 1: 30-39.

\section{Published Version}

doi:10.1056/nejmc1209366

\section{Permanent link}

http://nrs.harvard.edu/urn-3:HUL.InstRepos:13956367

\section{Terms of Use}

This article was downloaded from Harvard University's DASH repository, and is made available under the terms and conditions applicable to Other Posted Material, as set forth at http:// nrs.harvard.edu/urn-3:HUL.InstRepos:dash.current.terms-of-use\#LAA

\section{Share Your Story}

The Harvard community has made this article openly available.

Please share how this access benefits you. Submit a story.

Accessibility 


\title{
Cognitive Trajectories after Postoperative Delirium
}

\author{
Jane S. Saczynski, Ph.D., Edward R. Marcantonio, M.D., Lien Quach, M.P.H., M.S., \\ Tamara G. Fong, M.D., Ph.D., Alden Gross, Ph.D., M.P.H., \\ Sharon K. Inouye, M.D., M.P.H., and Richard N. Jones, Sc.D.
}

From the Division of Geriatric Medicine and Meyers Primary Care Institute, University of Massachusetts Medical School, Worcester (J.S.S.); and the Aging Brain Center, Institute for Aging Research, Hebrew SeniorLife (E.R.M., S.K.I., L.Q., T.G.F., A.G., R.N.J.), the Divisions of General Medicine and Primary Care (E.R.M.) and Gerontology (E.R.M., S.K.I., A.G., R.N.J.) and the Department of Neurology (T.G.F.), Beth Israel Deaconess Medical Center, and Harvard Medical School (E.R.M., S.K.I., T.G.F., R.N.J.) - all in Boston. Address reprint requests to $D r$. Saczynski at the Division of Geriatric Medicine, Department of Medicine, University of Massachusetts Medical School, 377 Plantation St., Suite 315, Worcester, MA 01605, or at jane.saczynski@umassmed.edu.

Drs. Saczynski and Marcantonio and Drs. Inouye and Jones contributed equally to this article.

N Engl J Med 2012;367:30-9. DOI: 10.1056/NEJMoal112923

Copyright (C) 2012 Massachusetts Medical Society.

\section{BACKGROUND}

Delirium is common after cardiac surgery and may be associated with long-term changes in cognitive function. We examined postoperative delirium and the cognitive trajectory during the first year after cardiac surgery.

\section{METHODS}

We enrolled 225 patients 60 years of age or older who were planning to undergo coronary-artery bypass grafting or valve replacement. Patients were assessed preoperatively, daily during hospitalization beginning on postoperative day 2, and at 1,6 , and 12 months after surgery. Cognitive function was assessed with the use of the MiniMental State Examination (MMSE; score range, 0 to 30, with lower scores indicating poorer performance). Delirium was diagnosed with the use of the Confusion Assessment Method. We examined performance on the MMSE in the first year after surgery, controlling for demographic characteristics, coexisting conditions, hospital, and surgery type.

\section{RESULTS}

The 103 participants (46\%) in whom delirium developed postoperatively had lower preoperative mean MMSE scores than those in whom delirium did not develop (25.8 vs. 26.9, $\mathrm{P}<0.001)$. In adjusted models, those with delirium had a larger drop in cognitive function (as measured by the MMSE score) 2 days after surgery than did those without delirium (7.7 points vs. 2.1, $\mathrm{P}<0.001)$ and had significantly lower postoperative cognitive function than those without delirium, both at 1 month (mean MMSE score, 24.1 vs. $27.4 ; \mathrm{P}<0.001$ ) and at 1 year (25.2 vs. $27.2, \mathrm{P}<0.001)$ after surgery. With adjustment for baseline differences, the between-group difference in mean MMSE scores was significant 30 days after surgery $(\mathrm{P}<0.001)$ but not at 6 or 12 months $(\mathrm{P}=0.056$ for both). A higher percentage of patients with delirium than those without delirium had not returned to their preoperative baseline level at 6 months ( $40 \%$ vs. $24 \%, \mathrm{P}=0.01)$, but the difference was not significant at 12 months $(31 \%$ vs. $20 \%$, $\mathrm{P}=0.055$ ).

\section{CONCLUSIONS}

Delirium is associated with a significant decline in cognitive ability during the first year after cardiac surgery, with a trajectory characterized by an initial decline and prolonged impairment. (Funded by the Harvard Older Americans Independence Center and others.) 
OGNITIVE IMPAIRMENT IS COMMON AFter cardiac surgery, and prevention efforts have not always been successful. ${ }^{1-4} \mathrm{Al}-$ though a large proportion of patients return to their preoperative level of cognitive function within 3 months, ${ }^{5,6}$ many do not. Older age, lower educational level, and the presence of one or more coexisting conditions are risk factors for postoperative cognitive decline, but few potentially reversible risk factors have been identified. ${ }^{7-9} \mathrm{We}$ hypothesized that patients with postoperative delirium, a potentially preventable, acute confusional state, would have a more precipitous drop in cognitive function immediately after surgery and a slower rate of cognitive recovery in the following year.

Delirium affects up to three quarters of patients after cardiac surgery and is associated with adverse outcomes after both cardiac and noncardiac surgery, including postoperative death in the hospital or after discharge, functional decline, and increased health care costs. ${ }^{10-15}$ Although delirium may resolve during hospitalization, it may have long-term functional and cognitive consequences. ${ }^{11,16}$

Delirium has been associated with cognitive decline in general patient populations, ${ }^{17}$ but it is unclear whether delirium affects the return of cognitive function to preoperative levels after cardiac surgery. Investigation of this issue in the context of nonemergency surgery provides an opportunity to directly measure baseline cognitive function, which is an important methodologic advantage over studies addressing the same question in general medical and intensive care unit populations. We followed patients for 1 year after cardiac surgery, assessing them for both delirium and cognitive impairment in order to examine the effect of delirium on cognitive performance. We used the Mini-Mental State Examination (MMSE), ${ }^{18}$ a short test of global mental status, to measure cognitive performance.

\section{METHODS}

\section{STUDY ENROLLMENT}

We screened patients 60 years of age or older who were planning to undergo cardiac surgery (coronary-artery bypass grafting or valve replacement) at two academic medical centers and one Veterans Administration hospital. Of the 461 patients who met the eligibility criteria and were invited to participate, ${ }^{19} 200$ declined and 26 could not be enrolled for other reasons (Fig. 1). A total of 235 participants provided written informed consent and were enrolled before surgery. We did not obtain postoperative cognitive assessments for 10 of the enrolled participants owing to death or withdrawal; those patients were excluded, yielding a final sample of 225 . These 10 excluded patients were similar to the 225 patients included in the analysis with respect to age, functional status, and burden of coexisting conditions; however, they had lower preoperative MMSE scores (which range from 0 to 30, with lower scores indicating poorer cognitive performance): 25.0 versus $26.9(\mathrm{P}=0.03)$.

\section{PREOPERATIVE ASSESSMENT}

Patients underwent a standardized interview conducted by trained interviewers. Demographic characteristics, behavioral factors, physical function, coexisting conditions, and cognitive function were assessed. The interview included the MMSE (purchased from Psychological Assessment Resources). Although it has the potential for ceiling effects, we chose the MMSE as the measure of cognitive function because it is commonly used in hospitalized patients as part of an assessment for delirium. ${ }^{19-21}$ Functional ability was assessed by means of the Katz Index of Independence in Activities of Daily Living, on which scores range from 0 (complete dependence) to 12 (complete independence). ${ }^{22}$

\section{POSTOPERATIVE ASSESSMENTS}

Beginning on postoperative day 2 and continuing until discharge, patients underwent daily assessment for delirium. The brief delirium assessment (<20 minutes) included the MMSE, a digit-span test, the Confusion Assessment Method (CAM; a diagnostic algorithm to determine the presence or absence of delirium on the basis of four features: acute change with a fluctuating course, inattention, disorganized thinking, and altered level of consciousness), ${ }^{23}$ and the Delirium Symptom Interview (an interview that assesses the presence or absence of eight features of delirium, including the four features of the CAM diagnostic algorithm). ${ }^{24}$ Delirium was rated as absent or present on the basis of the CAM, with supporting evidence from the MMSE, the digit-span test, and the Delirium Symptom Interview. The CAM has high sensitivity (94\%) and specificity (98\%) for ratings of delirium by geriatric psychiatrists. ${ }^{25}$ If a patient was intubated, then assessment for delirium was performed 


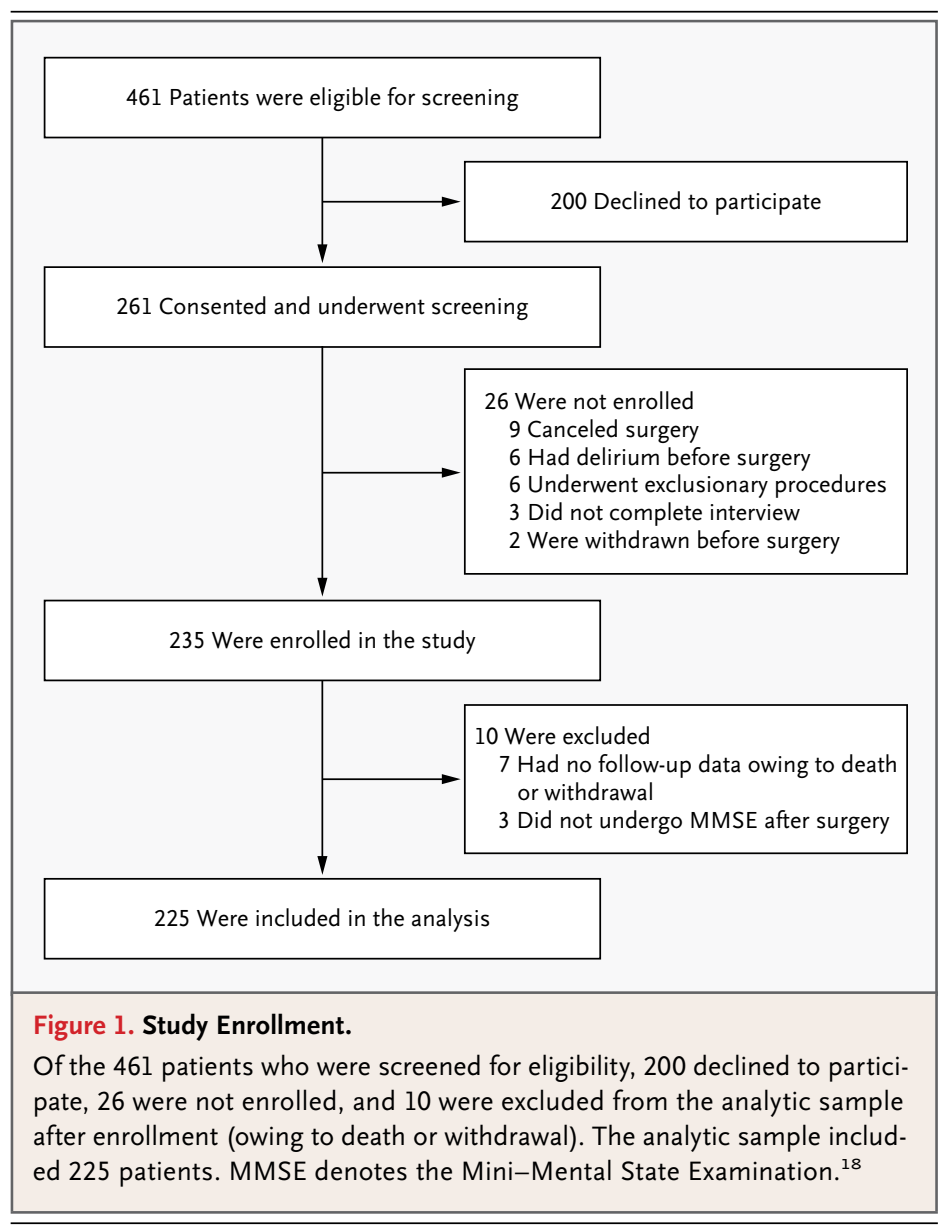

with the use of the CAM for the Intensive Care Unit, a validated nonverbal version of the CAM. ${ }^{26}$ Our combined assessment for delirium was highly reliable $(\mathrm{kappa}=0.95) .{ }^{27}$

As we expected, there were times when we were unable to perform the daily delirium assessments. Overall, $24.4 \%$ of the daily delirium assessments were missing because of patient or staff unavailability (e.g., weekend staffing). The percentage of missing assessments did not differ significantly between the patients with and those without delirium (24.7\% and $24.1 \%$, respectively). All patients underwent at least one delirium assessment on postoperative day 2 or 3 .

Daily interviews (including the MMSE, digitspan test, and other assessment tools) to assess the patients for delirium were supplemented by reviewing the medical records for evidence of clinical features of delirium. The Charlson comorbidity index, ${ }^{28}$ a weighted sum of 17 medical conditions (with higher scores indicating a greater burden of illness), was also calculated.
The duration of delirium was calculated as the number of days between the initial positive delirium assessment and the final positive delirium assessment. ${ }^{19}$ After discharge, patients were interviewed in person in their homes or at other locations (e.g., a rehabilitation facility) at 1,6 , and 12 months to assess cognitive function.

\section{STATISTICAL ANALYSIS}

Baseline characteristics of the patients with and those without postoperative delirium were compared with the use of the chi-square test for categorical variables and analysis of variance for continuous variables. A hierarchical linear regression model was used to characterize the trajectory of MMSE scores over time. This framework was chosen because of its flexibility with the timing of patient interviews and the repeated observations in each patient over time. We examined the rate of postoperative cognitive change over five intervals from baseline (preoperative cognitive function): postoperative day 2, days 3 to 5 , days 6 to 30 , days 31 to 183, and days 184 to 365 or more. Postoperative delirium was included as a timeinvariant indicator variable. We constructed two models: the first examined MMSE scores over time in the overall population without regard to delirium status, and the second added delirium and a delirium-by-time interaction term to see how MMSE scores differed between the group of patients with delirium and the group without delirium, both at baseline and over time. Analyses were conducted with the use of SAS software, version 9.2 (SAS Institute), and Stata software, version 12.0 (StataCorp).

In estimating MMSE scores, we adjusted for age, educational level, sex, race or ethnic group, score on the Charlson comorbidity index, and presence or absence of a history of stroke or transient ischemic attack (TIA), since these factors were likely to be associated with the long-term cognitive trajectory and have also been shown to be associated with the risk of delirium. ${ }^{19,29}$ We also adjusted for surgery type and hospital. We did not adjust for status with respect to alcohol use because in previous work in this cohort, consumption of alcohol was not associated with delirium and only two patients reported problematic drinking (defined as five or more drinks per day for men and four or more for women). ${ }^{19,30}$ There were no cases of delirium tremens in hospitalized patients. We evaluated model fit by graphically dis- 


\begin{tabular}{|c|c|c|c|c|}
\hline Characteristic & $\begin{array}{l}\text { Total Patients } \\
(\mathrm{N}=\mathbf{2 2 5})\end{array}$ & $\begin{array}{l}\text { Patients with } \\
\text { Delirium } \\
(\mathrm{N}=103)\end{array}$ & $\begin{array}{l}\text { Patients without } \\
\text { Delirium } \\
(\mathrm{N}=122)\end{array}$ & P Value \\
\hline Age (yr) & $73 \pm 6.7$ & $75 \pm 6.5$ & $72 \pm 6.6$ & $<0.001$ \\
\hline Female sex (\%) & 24 & 30 & 19 & 0.05 \\
\hline Educational level (\%) & & & & 0.05 \\
\hline Some high school or less & 16 & 19 & 12 & \\
\hline High school completed & 33 & 38 & 29 & \\
\hline College or more & 51 & 43 & 59 & \\
\hline Nonwhite race or Hispanic ethnic group (\%) & 4 & 7 & 2 & 0.05 \\
\hline Charlson comorbidity index score $†$ & $2.3 \pm 1.9$ & $2.7 \pm 2.1$ & $2.0 \pm 1.7$ & 0.01 \\
\hline Surgery type (\%) & & & & 0.25 \\
\hline CABG only & 78 & 75 & 81 & \\
\hline Valve replacement or valve replacement with $C A B G$ & 22 & 25 & 19 & \\
\hline History of stroke or transient ischemic attack (\%) & 18 & 23 & 13 & 0.04 \\
\hline Score for activities of daily living & & & & 0.13 \\
\hline Median & 12 & 12 & 12 & \\
\hline Range & $0-12$ & $0-12$ & $9-12$ & \\
\hline Any dependence (\%) & 5 & 7 & 3 & 0.21 \\
\hline MMSE score $\mathbb{S}$ & & & & $<0.001$ \\
\hline Median & 27 & 26 & 28 & \\
\hline Interquartile range & $25-29$ & $24-28$ & $27-29$ & \\
\hline
\end{tabular}

* Plus-minus values are means \pm SD. CABG denotes coronary-artery bypass grafting.

$\uparrow$ The score on the Charlson comorbidity index reflects a weighted sum of 17 medical conditions, with scores ranging from 0 to 37 and with higher scores indicating a greater burden of illness. ${ }^{28}$

$\uparrow$ Scores on the Katz Index of Independence in Activities of Daily Living scale range from 0 (complete dependence) to 12 (complete independence). ${ }^{22}$ "Any dependence" was defined as a score of less than 12.

$\int$ Scores on the Mini-Mental State Examination (MMSE) range from 0 to 30, with lower scores indicating poorer cognitive performance. $^{18}$

playing residuals and estimating the correlation between observed and estimated MMSE scores. ${ }^{31}$ We summarized the model results by computing, tabulating, and plotting the expected MMSE scores, given the model parameters, and we obtained interval estimates with bootstrap methods. In a secondary analysis, we used logistic regression to examine the probability that a follow-up MMSE score was lower than the preoperative (baseline) score as a function of time after surgery and delirium status.

To further support our findings, we conducted a series of sensitivity analyses. First, to address baseline differences in MMSE scores according to delirium status, we repeated the analysis, with patients in whom delirium developed individually matched according to baseline score to patients drawn (with replacement) from the group without postoperative delirium. Second, we examined the duration of delirium ( 1 to 2 days vs. $\geq 3$ days) in relation to the trajectory of cognitive function. Third, we excluded seven patients who had a stroke postoperatively. Finally, we used a rank-based transformation of MMSE scores as the outcome variable to address nonnormal distribution of scores. $^{32}$

\section{RESULTS}

\section{CHARACTERISTICS OF THE PATIENTS}

The mean $( \pm S D)$ age of the patients was $73 \pm 6.7$ years (range, 60 to 90). Approximately one quarter were women, and most were white and nonHispanic (Table 1). The median follow-up time was 363 days (range, 2 to 482). There was no significant difference in the mean follow-up time between the group of patients with delirium and the group without delirium (358 days [range, 


\begin{tabular}{|c|c|c|}
\hline Time of Assessment & $\begin{array}{l}\text { Estimated Score } \\
\qquad(95 \% \mathrm{Cl}) \dagger\end{array}$ & $\begin{array}{c}\text { Estimated Daily Change } \\
\text { during Interval }(95 \% \mathrm{CI}) \\
\text { points }\end{array}$ \\
\hline Before surgery & 26.9 (26.5 to 27.3$)$ & \\
\hline \multicolumn{3}{|l|}{ After surgery } \\
\hline Day 2 & 22.3 & $-4.6(-5.2$ to -4.0$)$ \\
\hline Days 3-5 & 25.4 & 1.04 (0.8 to 1.2 ) \\
\hline Days 6-30 & 26.3 & $0.036(0.01$ to 0.06$)$ \\
\hline Days 31-183 & 26.9 & $0.004(<0.001$ to 0.008$)$ \\
\hline Days 184-365 & 26.7 & $-0.001(-0.004$ to 0.002$)$ \\
\hline
\end{tabular}

* The estimated score before surgery was the baseline score. Estimates were adjusted for age, educational level, sex, race or ethnic group, score on the Charlson comorbidity index, presence or absence of a history of stroke or transient ischemic attack, hospital, and surgery type. $\mathrm{Cl}$ denotes confidence interval.

$\dagger$ The estimated score is for the last day of the interval.

2 to 427] and 368 days [range, 3 to 482], respectively; $\mathrm{P}=0.16$ ).

Postoperative delirium developed in $46 \%$ of patients (103 of 225 patients), with delirium lasting 1 to 2 days in $65 \%$ of these patients and 3 or more days in $35 \%$. As compared with patients without postoperative delirium, those with delirium were significantly older, less educated, more likely to be women, and less likely to be white (Table 1). In addition, patients with delirium were more likely to have a history of stroke or TIA and had a higher average score on the Charlson comorbidity index and a lower level of preoperative cognitive function.

\section{COGNITIVE-FUNCTION SCORES}

Using multilevel modeling, we examined the change in cognitive function from before surgery to 1 year after surgery in the overall study population. Our final model fit well $\left(r^{2}=0.76\right)$. With adjustment for age, sex, educational level, race or ethnic group, presence or absence of a history of stroke or TIA, score on the Charlson comorbidity index, surgery type, and hospital, the model-estimated MMSE score for all patients before surgery was 26.9. There was a significant decline in cognitive function of 4.6 points on the MMSE from baseline to postoperative day $2(\mathrm{P}<0.001)$ (Table 2$)$. This initial drop was followed by significant increases in cognitive function of 1 point on the MMSE each day on days 3 to $5(\mathrm{P}<0.001)$. The rate of improvement slowed considerably from day 6 to day 183. After day 183, cognitive performance stabilized, with no significant change from day 184 to day 365 after surgery (Table 2).

\section{COGNITIVE TRAJECTORIES ACCORDING TO DELIRIUM STATUS}

The trajectory of cognitive function varied significantly according to delirium status over the entire follow-up period (Table 3 and Fig. 2A). Patients with postoperative delirium had significantly lower estimated MMSE scores preoperatively than those without delirium ( 25.8 vs. 26.9 , $\mathrm{P}<0.001)$. These estimates differ from the values in Table 1 because they reflect adjustment for covariates. The patients in whom delirium developed had a greater decline in cognitive function immediately after surgery than did those without delirium (7.7 points vs. 2.1, $\mathrm{P}<0.001$ ). Although the initial decline in the MMSE score was larger among patients with delirium, the rate of recovery among these patients during postoperative days 3 to 5 was more rapid. The rate of recovery from days 6 to 30 was the same in the two groups (Table 3). However, from days 31 to 183, the perday increase in the MMSE score was 0.01 points higher for the patients with delirium than for those without delirium. Over this period, the patients without delirium had relatively stable scores, whereas those with delirium had an average gain of 1.2 points. With adjustment for baseline differences in MMSE scores between patients with and those without delirium, the mean scores at 6 and 12 months after surgery did not differ significantly between the groups $(\mathrm{P}=0.06)$ (Table 3$)$.

Although both groups had increases in adjusted MMSE scores in the year after surgery, relative to their scores immediately after surgery, patients without delirium returned to their preoperative level of cognitive function by approximately 1 month after surgery, whereas patients with delirium had not returned to their preoperative level of function by 1 year postoperatively (Table 3 and Fig. 2A). In addition, the proportion of patients who did not return to their preoperative level of function was significantly higher in the group with delirium than in the group without delirium through 6 months postoperatively ( $40 \%$ vs. $24 \%, \mathrm{P}=0.01$ ), but this proportion was not significantly different at 12 months (31\% and $20 \%$, respectively; $\mathrm{P}=0.06$ ) (Table 3 ). 


\begin{tabular}{|c|c|c|c|c|c|c|c|c|}
\hline \multirow[t]{2}{*}{ Day of Assessment } & \multicolumn{2}{|c|}{ Estimated Score } & \multicolumn{3}{|c|}{ Difference in Estimated Score } & \multicolumn{3}{|c|}{$\begin{array}{l}\text { Patients with Score } \\
\text { below Baseline }{ }^{\dagger}\end{array}$} \\
\hline & Delirium & $\begin{array}{c}\text { No } \\
\text { Delirium }\end{array}$ & $\begin{array}{l}\text { Absolute } \\
\text { Difference }\end{array}$ & $\begin{array}{l}\text { Net Effect } \\
(95 \% \mathrm{Cl})\end{array}$ & P Value & $\begin{array}{l}\text { Delirium } \\
\text { perc }\end{array}$ & $\begin{array}{l}\text { No } \\
\text { Delirium } \\
\text { cent }\end{array}$ & P Value \\
\hline Before surgery & 25.8 & 26.9 & 1.1 & & & & & \\
\hline \multicolumn{9}{|l|}{ After surgery } \\
\hline Day 2 & 18.1 & 24.8 & 6.7 & $-5.6(-6.6$ to -4.6$)$ & $<0.001$ & 88 & 59 & $<0.001$ \\
\hline Day 5 & 23.3 & 26.6 & 3.3 & $-2.2(-2.8$ to -1.3$)$ & $<0.001$ & 82 & 51 & $<0.001$ \\
\hline Day 30 & 24.1 & 27.4 & 3.3 & $-2.2(-2.8$ to -1.3$)$ & $<0.001$ & 64 & 37 & $<0.001$ \\
\hline Day 183 & 25.3 & 27.3 & 2.0 & $-0.9(-1.8$ to 0.0$)$ & 0.06 & 40 & 24 & 0.01 \\
\hline Day 365 and after & 25.2 & 27.2 & 2.0 & $-0.9(-1.8$ to 0.0$)$ & 0.06 & 31 & 20 & 0.055 \\
\hline
\end{tabular}

* Estimated or model-implied MMSE scores reflect parameter estimates from a mixed-effect regression model with adjustment for age, educational level, sex, race or ethnic group, score on the Charlson comorbidity index, history of stroke or transient ischemic attack, hospital, and surgery type. Estimates are for the 50th percentile and were obtained with the use of bootstrap resampling methods. Nonsignificant interactions between time and delirium were dropped from the model.

$\dagger$ The percentages below the baseline estimates are derived from a logistic-regression model. The regression parameter capturing the difference between the patients with and those without delirium in the expected proportion performing below baseline over time was significant $(P=0.003)$. Pointwise estimates of the difference in proportions were estimated with the use of 1001 bootstrap replications.

$\ddagger P$ values are for the model-implied net difference at the specified time points and are based on two-tailed tests.

\section{SENSITIVITY ANALYSES}

A sensitivity analysis with exact matching on the baseline MMSE score yielded similar results (Fig. $2 B$ ). A longer duration of delirium ( $\geq 3$ days vs. $<3$ days) was associated with a significantly greater drop in the score immediately after surgery and a slower recovery during the 1-year postoperative period (Fig. 2C). Results were also similar when we excluded patients who had a stroke postoperatively and when we used a rank-based transformation of MMSE scores to address nonnormal distribution (data not shown).

\section{DISCUSSION}

We found that delirium after cardiac surgery was associated with a postoperative cognitive trajectory characterized by an initial decline in performance on the MMSE and a prolonged period of impairment. After adjustment for baseline differences, the mean MMSE score did not differ significantly between the patients with and those without delirium 6 months and 1 year after surgery. However, patients with postoperative delirium were significantly less likely to have returned to their preoperative level of performance at 6 months than were patients without delirium. These findings suggest that delirium, which was once thought of as a short-term, transient cognitive disorder, may have longer-term observed effects on cognitive function in patients who have undergone cardiac surgery. This study establishes an association between delirium after cardiac surgery and cognitive dysfunction by means of preoperative and serial objective assessments of cognitive function and state-of-the-art assessments of delirium, both of which were not, to our knowledge, used in previous studies. ${ }^{33-38}$

With the aging of the patient population undergoing cardiac surgery and increases in survival after surgery, clinicians and patients are increasingly concerned with factors associated with quality of life, including cognitive status, as major outcomes of surgery. ${ }^{11,15}$ Although a high proportion of patients undergoing cardiac surgery have cognitive impairment immediately after the surgery, impairment diminishes in the weeks and months after discharge. ${ }^{6,39,40}$ Whether postoperative delirium is associated with prolonged cognitive dysfunction has been unclear.

The few studies that have addressed the effect of delirium on the course of cognitive function 


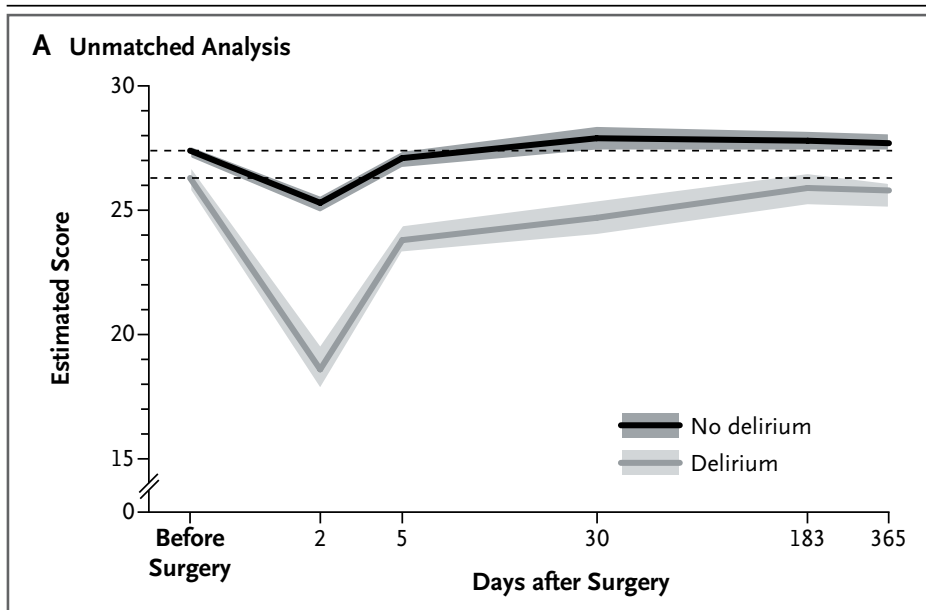

B Sensitivity Analysis with Matched Baseline Score

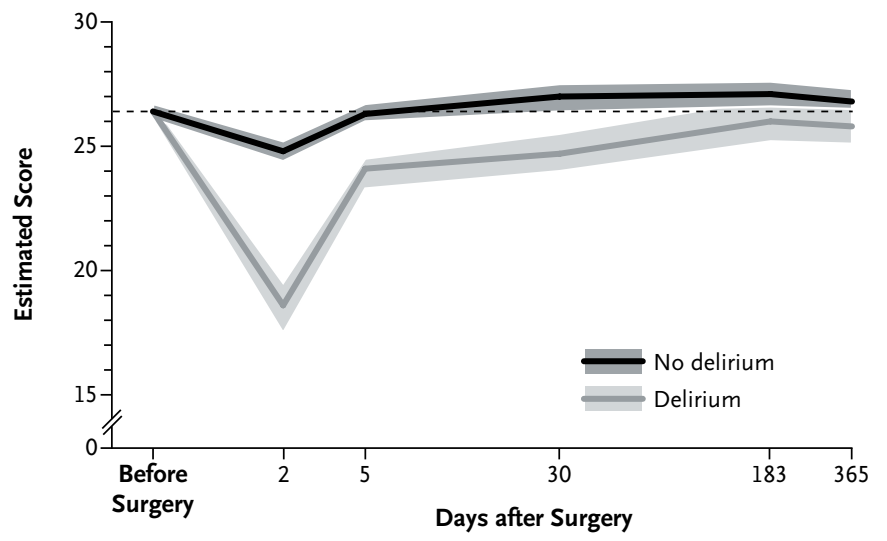

C Sensitivity Analysis with Duration of Delirium

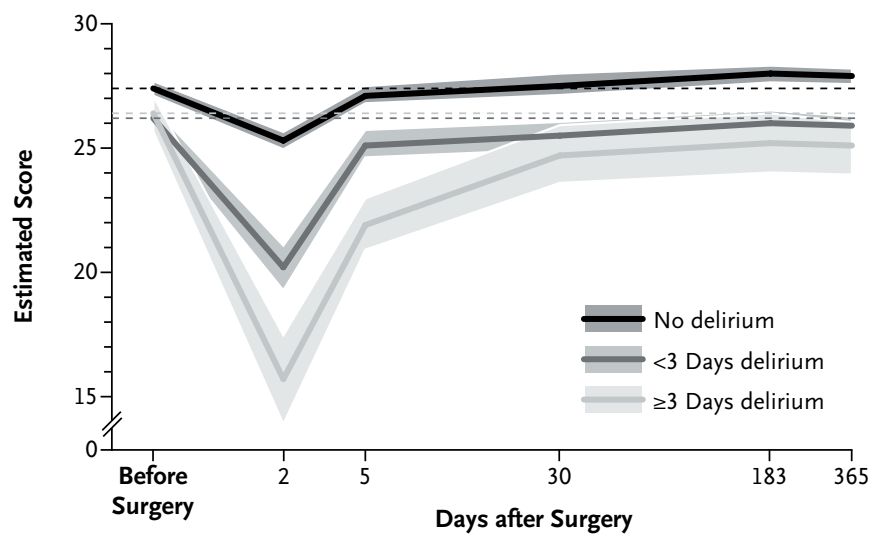

after cardiac surgery differed with respect to the timing and frequency of follow-up assessments. One study assessed cognitive function in $112 \mathrm{pa}-$ tients (delirium developed in 21\%) 1 to 1.5 years after cardiac surgery and showed that memory and concentration problems were more prevalent
Figure 2. Expected Scores on the MMSE after Cardiac Surgery in Patients with and Those without Postoperative Delirium.

Panel A shows the results of the main (unmatched) analysis of the 225 patients included in the study. Panel $B$ shows the results of the sensitivity analysis that matched the baseline MMSE scores of the patients with delirium to the scores of those without delirium. Panel $\mathrm{C}$ shows the results of the sensitivity analysis of the duration of delirium. Plotted curves and the bands indicating $95 \%$ confidence intervals reflect predicted values that were based on parameter estimates from a mixed-effects regression model that included adjustment for age, sex, educational level, race or ethnic group, hospital, presence or absence of a history of stroke or transient ischemic attack, score on the Charlson comorbidity index, ${ }^{28}$ and surgery type. The time axis is plotted in days on a log scale, but original units are labeled. Dashed lines indicate the baseline (preoperative) expected score for each group. Breaks in the lines (i.e., changes in line trajectories) and labeled time points correspond to separate intervals modeled in the multilevel regression model.

among patients with postoperative delirium than among those without delirium; however, preoperative cognitive function was not assessed. ${ }^{38}$ Hudetz et al. assessed cognitive function in 28 patients (delirium developed in 32\%) 1 week after surgery and found that patients with delirium were more than 10 times as likely as patients without delirium to have impaired memory and executive function. ${ }^{37}$ We assessed cognitive function preoperatively and an average of five times during the year after surgery, allowing us to accurately model the course of cognitive function and to compare the rate of recovery among patients with and those without postoperative delirium.

In our cohort, postoperative delirium was common, affecting $46 \%$ of patients. The rate of delirium is dependent on the methods used for its ascertainment, and our study used a rigorous assessment ${ }^{27}$ with diagnosis by means of the CAM, the most widely adopted, validated approach in the literature. ${ }^{21,25}$ Most of the extensive literature examining neurocognitive function after cardiac surgery has not integrated these methods of assessing delirium and therefore has not been able to address our specific study question. ${ }^{29,39,41,42}$

Our findings are of clinical significance, since the risk of delirium among patients undergoing cardiac surgery can be predicted preoperatively, and delirium is potentially preventable. ${ }^{19,43-45} \mathrm{Mul}-$ tifactorial proactive interventions such as the Hos- 
pital Elder Life Program ${ }^{43}$ have not been well tested in patients undergoing cardiac surgery. However, findings such as ours argue for further development and testing of such interventions. In patients with postoperative delirium, cognitive screening at hospital discharge may identify high-risk patients who require close monitoring after discharge or tailored transitional care in order to enhance functional and clinical outcomes.

Although patients without delirium did not, on average, have significant gains in cognitive function beyond day 30, patients with postoperative delirium continued to have improvement throughout the 6-month postoperative period. Given that delirium is associated with poor functional recovery after cardiac surgery ${ }^{15}$ and that cognitive impairment is associated with poor functional recovery after hospital discharge (for any condition) ${ }^{46}$ our finding that cognitive function improves more slowly in patients with delirium than in those without delirium has implications for the duration of postoperative care and rehabilitation services after cardiac surgery. Since patients with postoperative delirium continue to have improvements in cognitive function up to 6 months after surgery, rehabilitation services, such as physical and occupational therapy, may need to be extended for these patients.

Several additional factors that we were unable to examine may have contributed to our findings. The lower level of cognitive function at baseline in the group with postoperative delirium, as compared with the group without delirium, may have been related to a greater burden of preexisting disease that was not fully addressed in our multivariate models. Postoperative cognitive decline in patients with delirium may be the continuation of a trajectory of decline that began before surgery. ${ }^{47}$ Since we did not perform multiple preoperative assessments over time and did not include a nonsurgical comparison group, our study cannot address this question. Nonetheless, our findings suggest that the development of postoperative delirium should be added to the list of risk factors for prolonged impairment after cardiac surgery, which includes the development of atrial fibrillation, ${ }^{48}$ a history of depression, ${ }^{49}$ a lower level of education, ${ }^{7}$ and preexisting cerebrovascular disease. ${ }^{7,50}$ As opposed to many of the other identified risk factors, delirium is preventable and treatable. ${ }^{43-45}$
In a sensitivity analysis, we controlled for baseline differences in cognitive function by matching patients with and those without postoperative delirium on preoperative MMSE scores, and the results did not change. We used sophisticated analytic methods that allowed the use of all available data and descriptions of nonlinear trajectories of cognitive function after surgery. However, several limitations should be noted. Our sample consisted of patients who were predominantly white and well educated and who were enrolled in a single geographic region, potentially limiting the generalizability of the findings. However, this study was conducted at multiple sites that included urban, rural, and socioeconomically diverse populations. In addition, the MMSE may lack the sensitivity to identify mild cognitive impairment; thus, it is possible that more sensitive measures would have shown a slower return to the preoperative level of function in the group of patients without postoperative delirium. We do not have data on cognitive function beyond 1 year after surgery and were unable to control for apolipoprotein $\mathrm{E}$ status, although on the basis of the current literature, its association with delirium remains unclear. ${ }^{51,52}$ Finally, as noted above, our study lacked a nonsurgical comparison group.

In conclusion, this prospective study of patients undergoing cardiac surgery showed that postoperative development of delirium was a risk factor for a decline in cognitive function and a prolonged period of impairment after surgery. Identifying patients at high risk for delirium ${ }^{19}$ and promoting the development of interventions to prevent delirium in patients undergoing cardiac surgery may reduce the rate of long-term cognitive impairment in this population. Patients in whom delirium develops after cardiac surgery may require further interventions and customized rehabilitation programs to optimize recovery.

Supported by grants from the Harvard Older Americans Independence Center (P60AG008812), the National Institute on Aging (K01AG33643, to Dr. Saczynski), the National Heart, Lung, and Blood Institute (U01HL105268, to Dr. Saczynski), and the National Institute on Aging (R01AG030618, to Dr. Marcantonio, and P01AG031720, to Dr. Inouye), and by a National Institutes of Health (NIH) Mid-Career Investigator Award (K24AG035075, to Dr. Marcantonio) and an NIH Translational Research in Aging fellowship (T32 AG023480, to Dr. Gross). No potential conflict of interest relevant to this article was reported.

Disclosure forms provided by the authors are available with the full text of this article at NEJM.org.

We thank Daniel Habtemariam, Margaret Puelle, Eva Schmitt, Ph.D., Doug Tommet, M.P.H., and Kerry Palihnich. 
1. Raymond PD, Hinton-Bayre AD, Radel M, Ray MJ, Marsh NA. Assessment of statistical change criteria used to define significant change in neuropsychological test performance following cardiac surgery. Eur J Cardiothorac Surg 2006; 29:82-8.

2. Andrew MJ, Baker RA, Bennetts J, Kneebone AC, Knight JL. A comparison of neuropsychologic deficits after extracardiac and intracardiac surgery. J Cardiothorac Vasc Anesth 2001;15:9-14.

3. Fearn SJ, Pole R, Wesnes K, Faragher EB, Hooper TL, McCollum CN. Cerebral injury during cardiopulmonary bypass: emboli impair memory. J Thorac Cardiovasc Surg 2001;121:1150-60.

4. Cook DJ, Huston J III, Trenerry MR, Brown RD Jr, Zehr KJ, Sundt TM III. Postcardiac surgical cognitive impairment in the aged using diffusion-weighted magnetic resonance imaging. Ann Thorac Surg 2007;83:1389-95.

5. Müllges W, Berg D, Schmidtke A, Weinacker B, Toyka KV. Early natural course of transient encephalopathy after coronary artery bypass grafting. Crit Care Med 2000;28:1808-11.

6. Selnes OA, Grega MA, Borowicz LM Jr, Royall RM, McKhann GM, Baumgartner WA. Cognitive changes with coronary artery disease: a prospective study of coronary artery bypass graft patients and nonsurgical controls. Ann Thorac Surg 2003;75:1377-84.

7. Ho PM, Arciniegas DB, Grigsby J, et al. Predictors of cognitive decline following coronary artery bypass graft surgery. Ann Thorac Surg 2004;77:597-603.

8. Newman MF, Croughwell ND, Blumenthal JA, et al. Predictors of cognitive decline after cardiac operation. Ann Thorac Surg 1995;59:1326-30.

9. Collison T, Smith JM, Engel AM. Peripheral vascular disease and outcomes following coronary artery bypass graft surgery. Arch Surg 2006;141:1214-8.

10. Marcantonio ER, Goldman L, Mangione $\mathrm{CM}$, et al. A clinical prediction rule for delirium after elective noncardiac surgery. JAMA 1994;271:134-9.

11. Rudolph JL, Schreiber KA, Culley DJ, et al. Measurement of post-operative cognitive dysfunction after cardiac surgery: a systematic review. Acta Anaesthesiol Scand 2010;54:663-77.

12. Franco K, Litaker D, Locala J, Bronson D. The cost of delirium in the surgical patient. Psychosomatics 2001;42:68-73.

13. Sockalingam S, Parekh N, Bogoch II, et al. Delirium in the postoperative cardiac patient: a review. J Card Surg 2005; 20:560-7.

14. Gottesman RF, Grega MA, Bailey $M M$, et al. Delirium after coronary artery bypass graft surgery and late mortality. Ann Neurol 2010;67:338-44.

15. Rudolph JL, Inouye SK, Jones RN, et al. Delirium: an independent predictor of functional decline after cardiac surgery. J Am Geriatr Soc 2010;58:643-9.

16. Loponen P, Luther M, Wistbacka JO, et al. Postoperative delirium and health related quality of life after coronary artery bypass grafting. Scand Cardiovasc J 2008; 42:337-44.

17. Jackson JC, Gordon SM, Hart RP, Hopkins RO, Ely EW. The association between delirium and cognitive decline: a review of the empirical literature. Neuropsychol Rev 2004;14:87-98.

18. Folstein MF, Folstein SE, McHugh PR "Mini-Mental State": a practical method for grading the cognitive state of patients for the clinician. J Psychiatr Res 1975;12 189-98.

19. Rudolph JL, Jones RN, Levkoff SE, et al. Derivation and validation of a preoperative prediction rule for delirium after cardiac surgery. Circulation 2009;119:229-36. 20. Anthony JC, LeResche L, Niaz U, von Korff MR, Folstein MF. Limits of the 'Mini-Mental State' as a screening test for dementia and delirium among hospital patients. Psychol Med 1982;12:397-408.

21. Wong CL, Holroyd-Leduc J, Simel DL, Straus SE. Does this patient have delirium? Value of bedside instruments. JAMA 2010, 304:779-86

22. Katz S, Downs TD, Cash HR, Grotz RC. Progress in development of the index of ADL. Gerontologist 1970;10:20-30.

23. Inouye SK, van Dyck $\mathrm{CH}$, Alessi CA, et al. Clarifying confusion: the Confusion Assessment Method: a new method for detection of delirium. Ann Intern Med 1990;113:941-8.

24. Albert MS, Levkoff SE, Reilly C, et al. The delirium symptom interview: an interview for the detection of delirium symptoms in hospitalized patients. J Geriatr Psychiatry Neurol 1992;5:14-21.

25. Wei LA, Fearing MA, Sternberg EJ, Inouye SK. The Confusion Assessment Method: a systematic review of current usage. J Am Geriatr Soc 2008;56:823-30.

26. Ely EW, Inouye SK, Bernard GR, et al. Delirium in mechanically ventilated patients: validity and reliability of the Confusion Assessment Method for the Intensive Care Unit (CAM-ICU). JAMA 2001; 286:2703-10.

27. Simon SE, Bergmann MA, Jones RN, Murphy KM, Orav EJ, Marcantonio ER. Reliability of a structured assessment for nonclinicians to detect delirium among new admissions to postacute care. J Am Med Dir Assoc 2006;7:412-5.

28. Charlson ME, Pompei P, Ales KL, MacKenzie CR. A new method of classify- ing prognostic comorbidity in longitudinal studies: development and validation. J Chronic Dis 1987;40:373-83.

29. Selnes OA, Gottesman RF, Grega MA, et al. Cognitive and neurologic outcomes after coronary-artery bypass surgery. N Engl J Med 2012;366:250-7.

30. NIAAA council approves definition of binge drinking. National Institute for Alcohol Abuse and Alcoholism (NIAAA) Newsletter. Winter 2004:3 (http://pubs .niaaa.nih.gov/publications/Newsletter/ winter2004/Newsletter_Number3.pdf). 31. Singer JD, Willett JB. Applied longitudinal data analysis: modeling change and event occurrence. New York: Oxford University Press, 2003.

32. Blom G. Statistical estimates and transformed beta variables. New York: John Wiley, 1958.

33. Kat MG, Vreeswijk R, de Jonghe JF, et al. Long-term cognitive outcome of delirium in elderly hip surgery patients: a prospective matched controlled study over two and a half years. Dement Geriatr Cogn Disord 2008;26:1-8.

34. Gruber-Baldini AL, Zimmerman S, Morrison RS, et al. Cognitive impairment in hip fracture patients: timing of detection and longitudinal follow-up. J Am Geriatr Soc 2003;51:1227-36.

35. Girard TD, Jackson JC, Pandharipande PP, et al. Delirium as a predictor of long-term cognitive impairment in survivors of critical illness. Crit Care Med 2010; 38:1513-20.

36. Furlaneto ME, Garcez-Leme LE. Impact of delirium on mortality and cognitive and functional performance among elderly people with femoral fractures. Clinics (Sao Paulo) 2007;62:545-52.

37. Hudetz JA, Patterson KM, Byrne AJ, Pagel PS, Warltier DC. Postoperative delirium is associated with postoperative cognitive dysfunction at one week after cardiac surgery with cardiopulmonary bypass. Psychol Rep 2009;105:921-32.

38. Koster S, Hensens AG, van der Palen J. The long-term cognitive and functional outcomes of postoperative delirium after cardiac surgery. Ann Thorac Surg 2009; 87:1469-74.

39. Newman MF, Kirchner JL, PhillipsBute B, et al. Longitudinal assessment of neurocognitive function after coronaryartery bypass surgery. N Engl J Med 2001; 344:395-402. [Erratum, N Engl J Med 2001;344:1876.]

40. Knipp SC, Matatko N, Wilhelm H, et al. Cognitive outcomes three years after coronary artery bypass surgery: relation to diffusion-weighted magnetic resonance imaging. Ann Thorac Surg 2008;85:872-9. 41. Selnes OA, McKhann GM, Borowicz LM Jr, Grega MA. Cognitive and neurobe- 
havioral dysfunction after cardiac bypass procedures. Neurol Clin 2006;24:133-45.

42. McKhann GM, Goldsborough MA, Borowicz LM Jr, et al. Cognitive outcome after coronary artery bypass: a one-year prospective study. Ann Thorac Surg 1997; 63:510-5.

43. Inouye SK, Bogardus ST, Charpentier $\mathrm{PA}$, et al. A multicomponent intervention to prevent delirium in hospitalized olde patients. N Engl J Med 1999;340:669-76.

44. Marcantonio ER, Flacker JM, Wright RJ, Resnick NM. Reducing delirium after hip fracture: a randomized trial. J Am Geriatr Soc 2001;49:516-22.

45. Maldonado JR, Wysong A, van der Starre PJ, Block T, Miller C, Reitz BA. Dexmedetomidine and the reduction of postoperative delirium after cardiac surgery. Psychosomatics 2009;50:206-17.

46. Sands LP, Yaffe K, Covinsky K, et al.
Cognitive screening predicts magnitude of functional recovery from admission to 3 months after discharge in hospitalized elders. J Gerontol A Biol Sci Med Sci 2003; 58:37-45.

47. Fong TG, Tulebaev SR, Inouye SK. Delirium in elderly adults: diagnosis, prevention and treatment. Nat Rev Neurol 2009;5:210-20.

48. Stanley TO, Mackensen GB, Grocott $\mathrm{HP}$, et al. The impact of postoperative atrial fibrillation on neurocognitive outcome after coronary artery bypass graft surgery. Anesth Analg 2002;94:290-5.

49. McKhann GM, Borowicz LM, Goldsborough MA, Enger C, Selnes OA. Depression and cognitive decline after coronary artery bypass grafting. Lancet 1997;349: 1282-4.

50. Goto T, Baba T, Honma K, et al. Magnetic resonance imaging findings and postoperative neurologic dysfunction in elderly patients undergoing coronary artery bypass grafting. Ann Thorac Surg 2001;72:137-42

51. Bryson G, Wyand A, Wozny D, Rees L, Taljaard M, Nathan H. A prospective cohort study evaluating associations among delirium, postoperative cognitive dysfunction, and apolipoprotein E genotype following open aortic repair. Can J Anaesth 2011;58:246-55.

52. Tagarakis GI, Tsolaki-Tagaraki F, Tsolaki M, Diegeler A, Tsilimingas NB, Papassotiropoulos A. The role of apolipoprotein $\mathrm{E}$ in cognitive decline and delirium after bypass heart operations. Am J Alzheimers Dis Other Demen 2007; 22:223-8.

Copyright (c) 2012 Massachusetts Medical Society.

NEJM 200TH ANNIVERSARY AND SOCIAL MEDIA

Follow NEJMTeam on Twitter and click "Like" on the New England Journal of Medicine page on Facebook for links to the latest articles, stories, and multimedia available at the NEJM 200th Anniversary website, http://NEJM200.NEJM.org.

Tweets incorporating the hashtag \#NEJM200 also appear in a Twitter feed at the anniversary website.

The New England Journal of Medicine 